\title{
Transpalatal approach to the maxillary division of the trigeminal nerve for alcohol block
}

\author{
C. NORMAN SHEALY ${ }^{1}$, BENJAMIN KAUFMAN, AND ANTHONY J. TOMARO \\ From the Division of Neurosurgery, Department of Radiology, Western Reserve \\ University School of Medicine, and School of Dental Surgery, and University Hospitals \\ of Cleveland, Cleveland, Ohio, U.S.A.
}

Occasionally an old procedure experiences a popular revival; similarly, one subspecialist may chance to learn an excellent technique from a colleague in another field. Recent experience with an approach to the sphenopalatine ganglion aroused our interest in a well-known dental technique which was formerly used by otolaryngologists and is currently used by oral surgeons but which has not, to our knowledge, been standard among neurosurgeons.

Sluder (1918) popularized the sphenopalatine ganglion as the seat of neurological symptoms, including 'cluster' or 'Horton's' headaches. Neurosurgical publications have refuted this and attacks upon the ganglion are generally considered ill-advised now. We do not propose to enter the controversy as to aetiology or treatment of this entire syndrome, but should like to report some pertinent neuro-anatomical considerations concerning the maxillary nerve.

It is of some interest that, despite considerable discussion of the sphenopalatine ganglion, little has been said of surgical approaches to it. Moreover, even when an approach is mentioned, it is usually described without noting the proximity of the entire maxillary division of the fifth cranial nerve (White and Sweet, 1955).

Older otolaryngological texts (Morrison, 1948) and current dental surgery texts (Thoma, 1963) describe briefly an anatomical approach with a needle to the pterygopalatine fossa which is simple and guides one directly into the fossa. However, noone has reported the radiological analysis of this approach. Simple lateral and anterior-posterior $x$-ray films of the skull will immediately confirm the position of the needle and allow greater accuracy in injection of alcohol.

\section{NEURO-ANATOMICAL AND RADIOLOGICAL APPROACH}

The maxillary division of the trigeminal nerve passes through the foramen rotundum into the pterygo'Present address: Gundersen Clinic, La Crosse, Wisconsin 54601, U.S.A. palatine fossa where two branches are contiguous with the sphenopalatine ganglion which hangs like a grape from the major nerve trunk. The maxillary division at or near this point branches into the infraorbital nerve and posterior-superior alveolar branches (Cunningham, 1937).

On a lateral radiograph of the skull, the pterygomaxillary fissure is easily recognized, marked anteriorly by the posterior wall of the maxillary sinus and posteriorly by the base of the pterygoid process of the sphenoid base. Directly medial ando continuous with the pterygomaxillary fissure is the pterygopalatine fossa, marked medially by then orbital and sphenoid processes of the sphenoid and superiorly by the sphenoid body. The inferior orbital fissure is continuous medically and superiorly with the pterygopalatine fissure.

The pertinent foramen rotundum is situated in the base of the sphenoid, but because of its plane is not easily identified radiologically. This has led to the use of Water's projection to demonstrate the foramen. When the lateral approach to the foramen rotundum is used, the Water's view gives good monitoring as to depth of penetration.

Opposite the second upper molar there is a palpable depression in the palatal mucosa. With slight probing here, a no. 24 needle can be inserted into the greater palatine foramen leading directly through the greater palatine canal into the pterygopalatine fossa. The greater palatine foramen can be identified on submentovertical skull films (Fig. 1). Lesser palatine foramina, variable in size and number, are situated posterior to the greater palatine foramen. If the needle is inserted into one of the lesser foramina an easy passage to the pterygopalatine fossa may not be found. Almost immediately on emerging from the greater palatine canal, the needle is very close to the foramen rotundum. Two simple $x$-ray views now suffice to monitor the procedure. A Water's view will ascertain the relation of the needle to the foramen rotundum and a lateral view will give the exact degree of penetration into the pterygopalatine fossa. 


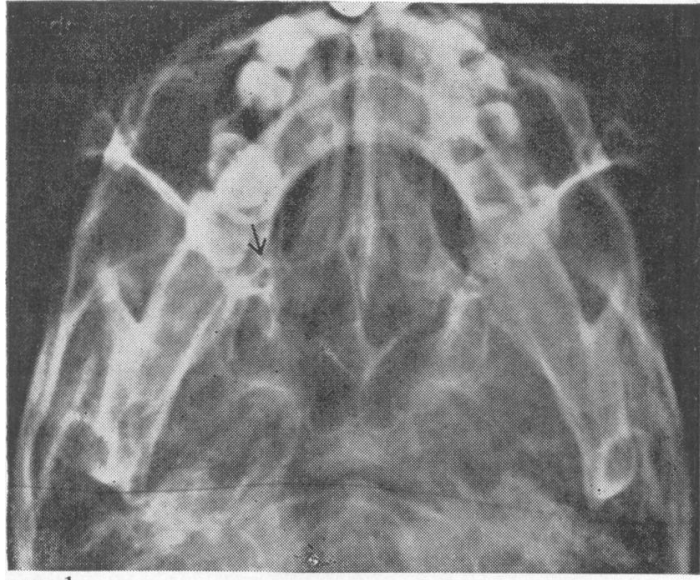

FIG. 1.

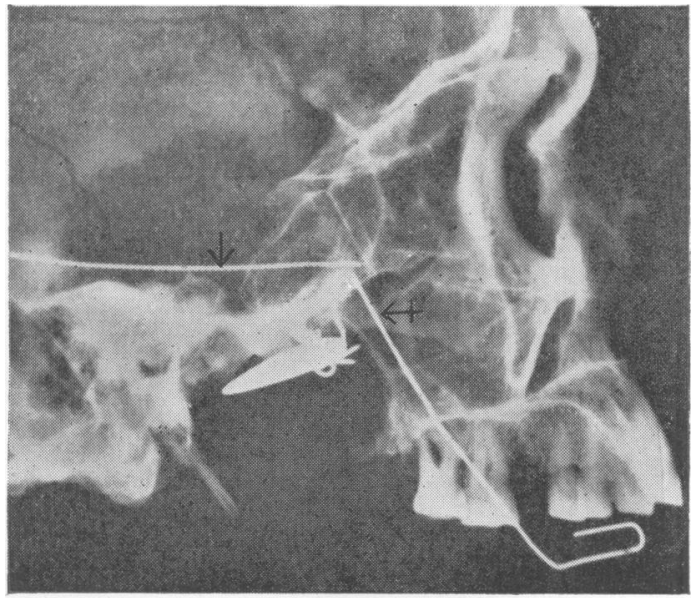

FIG. $2 \mathrm{a}$

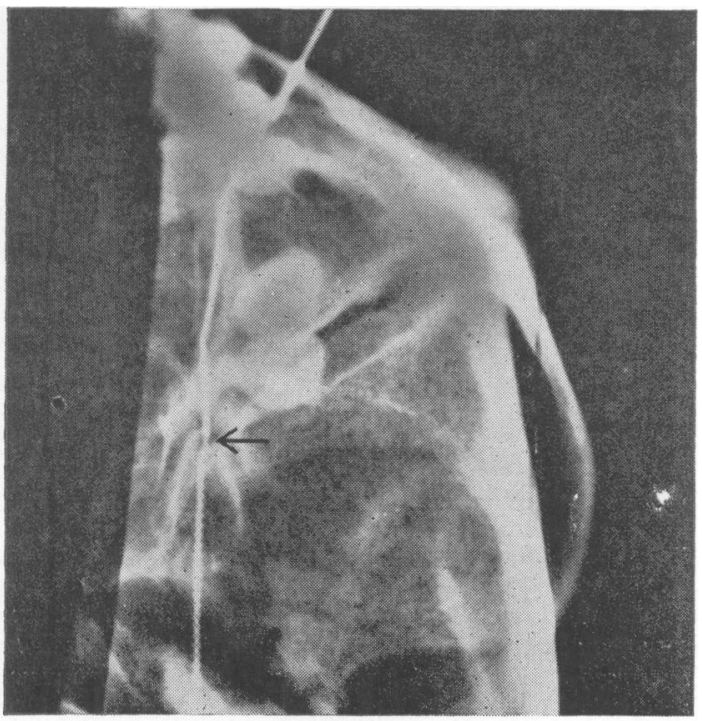

FIG. $2 b$.

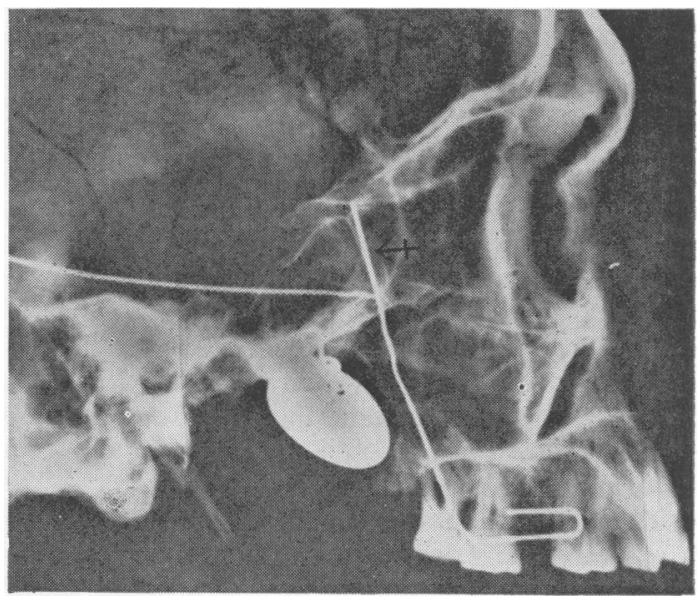

FIG. 3.

FIG. 1. Submentovertical view of a skull. The arrow points to the greater palatine foramen. Immediately posteriorly is a smaller lesser palatine foramen.

FIG. 2a. A lateral view of a skull specimen. The upper arrow points to the wire in a pipe cleaner which emerges anteriorly through the foramen rotundum. The lower arrow points to the section of a paper clip which is inserted through the greater palatine foramen and is in the inferior part of the pterygopalatine fossa.

FIG. 2b. A submentovertical view of half a skull specimen showing the meeting of the paper clip and the pipe cleaner wire at the foramen rotundum.

FIG. 3. Lateral view of a skull specimen showing that the paper clip has been advanced to the level of the optic foramen which is situated immediately below the planum sphenoidale. 
The tip of the needle enters the lower third of the fossa as viewed on the lateral radiographs (Figs, 2a and $2 \mathrm{~b}$ ). Deeper penetration may be necessary, but also advances the needle higher and closer to the important superior structures, optic nerves and extraocular nerves (Fig. 3). The course of the optic nerve can be identified either by considering the bony optic canal or by relating the portion of the optic canal to the planum sphenoidale. Since the needle is in a narrow bony canal, its course is fixed in two directions, leaving depth as the only variable. Actually, depth of not more than 2 or $3 \mathrm{~mm}$. into this fossa should suffice and this will avoid injury to the important optic and extraocular nerves.

We have found that a lateral view of the skull identifies exactly the position of the needle tip and establishes whether the needle is still in the greater palatine canal or has entered the inferior pterygopalatine fossa, the ideal area for alchohol injection.

In the traditional lateral approach, a Water's view is not necessary with transpalatine approach.

\section{CASE REPORT}

A brief résumé is given here of the patient who aroused our interest in the procedure described.

J.M. (U.H. NO. 744-916) This 24-year-old housewife underwent successful removal of a large neurinoma of the left gasserian ganglion in 1962. Afterwards she had total palsies of the left cranial nerves III, V, and VI and she

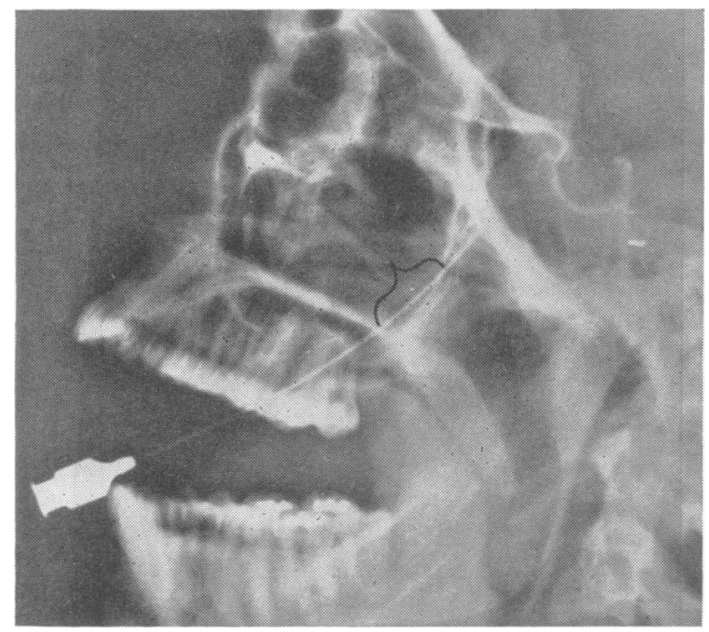

FIG. 4a. (Patient J.M.) Lateral view of skull. A no. 22 needle is seen traversing the greater palatine foramen. The tip of the needle is touching the sphenoid bone and penetration is in the lower part of the pterygopalatine fossa and well below the optic nerve. This penetration is deeper than necessary for initial injection. complained of severe rhinorrhoea from the left nostril. Numerous tests for sugar were negative so that we were convinced that this probably represented unchecked nasal secretions, perhaps aggravated by some interference with autonomic supply to the nasal mucosa. Antihistaminesand anticholinergic drugs failed to help. A temporary block of the left sphenopalatine ganglion with xylocaine gave transient dryness of the left nose.

On 12 December 1964 the region of the left sphenopalatine ganglion visible radiologically was injected with $1 \mathrm{ml}$. absolute alcohol inserted through a no. 22 needle passed through the greater palatine foramen into the pterygopalatine fossa (Figs. $4 a$ and $4 b$ ).

After this procedure there was satisfactory dryness of the left nose for six months, with gradual return of secretions over the next two months.

One of us (A.J.T.) has used this approach for a number of years to block the maxillary division of the trigeminal nerve, with excellent results. Recently we have easily performed by this route a maxillary block in a patient with trigeminal neuralgia.

\section{DISCUSSION}

Eagle (1942) gives a long discussion of sphenopalaㅁำ tine ganglion neuralgia; mostly he treated this witp cocaine placed behind the middle nasal turbinate He mentions alcohol injections into the ganglion vis this route in five patients, but says the procedure not without danger'.

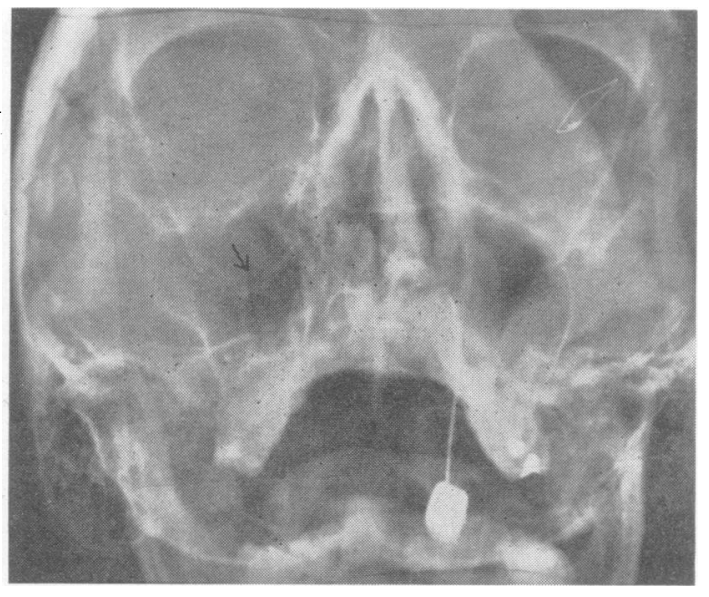

FIG. 4b. Water's projection showing course of the needle. The right foramen rotundum is seen and the depth relationship of the tip of the needle to the unvisualized left foramen rotundum can be appreciated. However, since the needle has $\mathrm{J}$ traversed a small canal, it is obvious that the lateral view is the critical one. 
Sluder (1918) recommended alcohol injection into the ganglion, but mentions the possibility of haemorrhage when this is done through the nose. As late as 1948 Morrison described alcohol injection of the sphenopalatine ganglion through the 'posterior palatine canal' (Sluder, 1918). Two textbooks (Boies, Hilger and Priest, 1964; DeWeese and Saunders, 1964) do not describe this technique.

Cushing (1920), in his first paper on trigeminal neuralgia, refers to 'extracranial severance' of the maxillary nerve which is bound to occur with excision of Meckel's ganglion; he considered injection of the ganglion intranasally a hazardous procedure. He mentions removal of Meckel's ganglion together with the maxillary division, achieved by enlarging the foramen rotundum through a typical subtemporal approach. He does mention a 'transnasal injection of Meckel's ganglion, with resulting numbness of the right palate and cheek' for one year.

For alcohol injection, neurosurgeons have most commonly approached the maxillary division introducing a needle percutaneously through a lateral approach into the pterygopalatine (pterygomaxillary) fossa as described by White and Sweet (1955). This is usually done as a relatively blind approach with dependence upon symptomatic spread of pain when the nerve or one of its branches is encountered by the needle. White and Sweet recommend a Water's $x$-ray view to see the foramen rotundum when there is difficulty encountering the nerve. Although largely successful, this traditional approach does not allow exact radiological localization of the needle tip since only one view is employed and it is quite possible that some of the reported ocular palsies from injection of alcohol are due to slightly deeper penetration to the nearby superior orbital fissure.

The 'traditional' lateral approach was developed, according to White and Sweet (1955), by Levy and Bandow and introduced into the U.S.A. by Patrick. Although it offers a good chance for success in experienced hands, many failures have been reported. The technique described above may prove useful as a simplified approach which can be controlled.

\section{SUMMARY}

An accurate, well-controlled and $x$-ray-monitored approach to the maxillary nerve is described. It has long been known to dental surgeons, although previously radiological monitoring has not been reported. This should eliminate some complications of second division trigeminal injections and we present this paper to acquaint others with the possibilities of such an approach.

\section{REFERENCES}

Boies, L. R., Hilger, J. A., and Priest, R. E. (1964). Fundamentals of Otolaryngology. 4th ed. W. B. Saunders, Philadelphia.

Cunningham's Textbook of Anatomy. (1937). Edited by J. C. Brash and E. B. Jamieson. 7th ed. p. 153. Oxford University Press, London.

Cushing, H. (1920). The Major Trigeminal Neuralgias and Their Surgical Treatment Based on Experiences with 332 Gasserian Operations. Amer. J. med. Sci. 160, 157-184.

DeWeese, D. D., and Saunders, W. H. (1964). Textbook of Otolaryngology. 2nd ed. C. V. Mosby, St. Louis.

Eagle, W. W. (1942). Sphenopalatine Ganglion Neuralgia. Arch. Otolaryng, 35, 66-84.

Morrison, W. W. (1948). In Diseases of the Ear, Nose and Throat. Appleton-Century-Crofts, New York.

Sluder, G. (1918). Concerning Some Headaches and Eye Disorders of Nasal Origin. C. V. Mosby, St. Louis.

Thoma, K. H. (1963). Oral Surgery. 4th ed. C. V. Mosby, St. Louis.

White, J. C., and Sweet, W. H. (1955). Pain-Its Mechanisms and Neurosurgical Control. Thomas, Springfield, Illinois. 